Technical Note

\title{
Easy-to-Use InDel Markers for Genetic Mapping between Col-0 and Ler-0 Accessions of Arabidopsis thaliana
}

\author{
Takahiro Tanaka, Yuichi Nishii, Hirotoshi Matsuo and Taku Takahashi * $\mathbb{C}$ \\ Graduate School of Natural Science and Technology, Okayama University, Okayama 700-8530, Japan; \\ pwkm6m8a@s.okayama-u.ac.jp (T.T.); ptkg9kuh@s.okayama-u.ac.jp (Y.N.); peu91tyx@s.okayama-u.ac.jp (H.M.) \\ * Correspondence: perfect@cc.okayama-u.ac.jp
}

Received: 1 June 2020; Accepted: 20 June 2020; Published: 22 June 2020

\begin{abstract}
Map-based gene cloning has played a key role in many genetic studies using the model plant, Arabidopsis thaliana. In the post- next generation sequencing era, identification of point mutations and their corresponding genes is increasingly becoming a powerful and important approach to define plant gene function. To perform initial mapping experiments efficiently on Arabidopsis mutants, enrichment of easy-to-use and reliable polymorphic DNA markers would be desirable. We present here a list of InDel polymorphic markers between Col-0 and Ler-0 accessions that can be detected in standard agarose gel electrophoresis.
\end{abstract}

Keywords: InDel markers; SSLP; chromosome mapping; Arabidopsis thaliana; mutants

\section{Introduction}

In the last decades, many genes have been identified from mutations by map-based cloning strategy in the model plant, Arabidopsis thaliana [1,2]. Even after the development of genetic engineering techniques such as CRISPR/Cas, which has proven to be a powerful tool for gene editing [3-6], isolation of point mutant alleles and identification of their corresponding genes still continue to be an indispensable approach to the study of gene function. With the advance of PCR technology, there have been various mapping tools and markers developed. These include cleaved amplified polymorphic sequences (CAPS) [7,8], simple sequence length polymorphisms (SSLP) also known as microsatellites [9] and derived CAPS (dCAPS) [10]. In the post-next generation sequencing (NGS) era, chromosome mapping with the use of these polymorphic markers remains an initial key step for rapid detection and identification of a mutant gene. This is both because the mutants isolated by chemically induced mutagenesis contain multiple mutations and because NGS data contains many sequencing errors.

To perform mapping experiments efficiently, insertion/deletion (InDel) markers including SSLP, which can discriminate genotypes without restriction digestion, have been further developed between Arabidopsis accessions [11,12] and, indeed, widely applied to many genetic studies. Information on these polymorphic markers is also available in the TAIR database (http://www.arabidopsis.org). However, it may not be simple to choose the markers appropriate for initial mapping experiments from the vast information compiled from many sources, which sometimes also contains incorrect data. One of the few disadvantages of these InDel markers is that most of them represent length polymorphisms of less than 30-40 bp and require electrophoresis in polyacrylamide or highly concentrated agarose gels for detection. On the other hand, the number of the markers with more length difference detectable in standard $0.8 \%-1.0 \%$ agarose gels is limited. A study by Zhang et al. [13] provides a useful list of InDel markers between Columbia-0 (Col-0) and Landsberg erecta-0 (Ler-0), the most frequently used 
accessions in Arabidopsis genetic studies, with a detailed protocol for map-based cloning. The list contains two InDel per chromosome for a total of ten markers. In order to save time and effort from initial rough mapping to final gene identification, further InDel markers would be desirable. Here, based on published papers and the information collected in the database, we provide a list of InDel markers between Col-0 and Ler-0 accessions that can be detected in standard agarose gel electrophoresis.

\section{Results and Discussion}

We searched for and selected InDel polymorphisms with length difference of more than $60 \mathrm{bp}$ between Col- 0 and Ler-0 accessions, which would be separable on $0.8 \%$ agarose gels, from the information available in the TAIR database (http://www.arabidopsis.org) and previously published papers [11-15]. Figure 1 summarizes the chromosome map position of all markers we have tested so far and judged to be appropriate for genotyping. The name of these markers is derived from the name of bacterial artificial chromosome (BAC) clones in which the InDel polymorphism exists, except for $\mathrm{BIO} 2 \mathrm{~b}, \mathrm{CIW} 28$ and DOG1 [15]. We recommend the markers asterisked in Figure 1 as a first choice for initial rough mapping because they are evenly distributed across the chromosomes and both upper and lower arms of each chromosome hosted at least one of them.

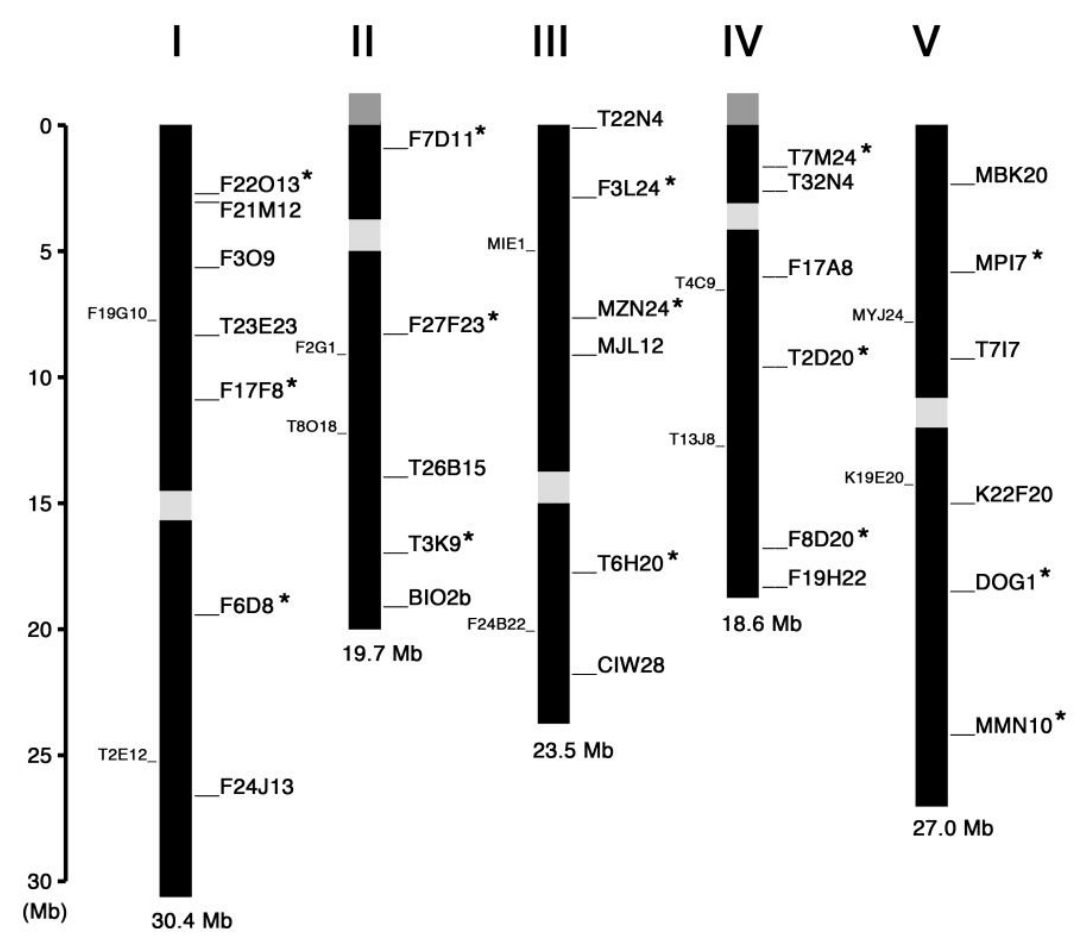

Figure 1. Linkage map of the InDel markers on Arabidopsis chromosomes. The markers examined in this study are indicated in the right-hand side of each chromosome whose number is shown on the top. The markers recommended as a first choice for rough mapping are asterisked. The InDel markers reported by Zhang et al. [13] are indicated in the left-hand side of each chromosome. The centromere regions are shown in light gray boxes. Nucleolus organizer regions coding for ribosomal RNAs are shown in dark gray boxes at the end of upper arm of chromosomes II and IV.

With only a few exceptions, we designed PCR primers to be 20 nucleotides in length with the GC content of 9 to 11 nucleotides and the $3^{\prime}$ ending with $\mathrm{G}$ or $\mathrm{C}$ to promote specific binding (Table 1 ). To prevent mispriming at GC-rich sequences and smearing of DNA bands in the gel, A or T was placed at the second position from the $3^{\prime}$ end and inclusion of more than 3 consecutive G/Cs near the $3^{\prime}$ end was avoided [16]. The length of amplified DNA fragments was generally set ranging from $300 \mathrm{bp}$ to $1000 \mathrm{bp}$. 
Table 1. PCR primer pair sequences used to examine the $30 \mathrm{InDel}$ markers of this study.

\begin{tabular}{|c|c|c|c|c|c|}
\hline Marker Name & Chr. & Position (Mbp) & Gene ID* & Length (bp) (Col-0/Ler) & Primer Sequence \\
\hline \multirow{2}{*}{$\mathrm{F} 22 \mathrm{O} 13$} & \multirow{2}{*}{1} & \multirow{2}{*}{2.826} & \multirow{2}{*}{ At1g04667 } & \multirow{2}{*}{$460 / 210$} & F: GTGTTGGGGAGAGCTTATAG \\
\hline & & & & & R: TCCACTTCCAACCATCAGAG \\
\hline \multirow{2}{*}{ F21M12 } & \multirow{2}{*}{1} & \multirow{2}{*}{3.138} & \multirow{2}{*}{$\begin{array}{l}\text { At1g09700 } \\
\text { (HYL1) }\end{array}$} & \multirow{2}{*}{$580 / 500$} & F: AAGACTCCATCTTGACACTG \\
\hline & & & & & R: CCTCAACCTACTGATCATTG \\
\hline \multirow{2}{*}{$\mathrm{F} 309$} & \multirow{2}{*}{1} & \multirow{2}{*}{5.653} & \multirow{2}{*}{$\begin{array}{l}\text { At1g16530 } \\
\text { (ASL9) }\end{array}$} & \multirow{2}{*}{$610 / 530$} & F: TTTTGGTCGGGTATGGAATG \\
\hline & & & & & R: CCAGAAGTTGCTCGTTAAAG \\
\hline \multirow{2}{*}{ T23E23 } & 1 & 8494 & At1g24000 & $540 / 420$ & F: AAGGTCTTGTAGCGATCTAG \\
\hline & 1 & 0.494 & $x_{0}=1000$ & $0+0 / 720$ & R: AACCCAACTGGCTCATTTTG \\
\hline F17F8 & 1 & 11.016 & At1g 30930 & $460 / 360$ & F: GGAAGAGGATTGACTCAAAG \\
\hline 1710 & 1 & 11.010 & 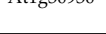 & $700 / 000$ & R: CTACCGCTAGGACTTTCATG \\
\hline F6D8 & 1 & 19.621 & At1g52690 & $640 / 540$ & F: GAGACACAGAGGAAGTGAAG \\
\hline FODO & 1 & 19.021 & $(L E A 7)$ & $0+0 / \partial+0$ & R: CTGACCAGCAAATTCTCAAG \\
\hline F24]13 & 1 & 26624 & At1g70610 & $600 / 500$ & F: GCTACCCTTCAAGAGATGAG \\
\hline $12+510$ & 1 & 20.024 & $(A B C B 26)$ & $000 / 300$ & R: TCGTAGAGTTGCAGCAAAAG \\
\hline F7D11 & 2 & 1614 & At $2 \mathrm{~g} 04622$ & $670 / 580$ & F: AGCGAACTTCGTTGATGTTC \\
\hline 17DIt & 2 & 1.014 & 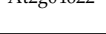 & $070 / 200$ & R: CAATGTATATGCTCTTCTAGAG \\
\hline $\mathrm{F} 27 \mathrm{~F} 23$ & 2 & 8.410 & At $2 g 19410$ & $460 / 400$ & F: TGACCAGTTGTACCAATGTG \\
\hline Г215 & 2 & 0.410 & सר & $400 / 400$ & R: GTCTGCGACAAAAAATACTG \\
\hline $\mathrm{T} 26 \mathrm{~B} 15$ & 2 & 13.825 & At2g32560 & $470 / 410$ & F: ААСАСАСТСТСТСТСТСТTG \\
\hline 120010 & 2 & 10.023 & 10080000 & $720 / 710$ & R: AGGTCAAGAACCGACATTTG \\
\hline T3K9 & 2 & 17.107 & At2g 40990 & $470 / 360$ & F: TCATCGGAAGGAGCATTATG \\
\hline $10 \mathrm{~N}$ & 2 & 17.107 & 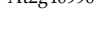 & $4 / 0 / 000$ & R: AGGATGTTCCAGAGAGAATG \\
\hline $\mathrm{BIO} 2 \mathrm{~b}$ & 2 & 18.012 & At2g43360 & $390 / 460$ & F: TGTACCTCCCTGAAGTTATG \\
\hline DIUZu & 2 & 10.012 & (BIO2) & $330 / 400$ & R: TCTTGACCTCCTCTTCCATG \\
\hline $\mathrm{T} 22 \mathrm{~N} 4$ & 3 & 0130 & At3g 01345 & $2040 / 400$ & F: TGACTGTTTGACTCCAAGTG \\
\hline $1221 \mathrm{~N} 4$ & 3 & 0.100 & 10 & $20+0 / 700$ & R: GTTACGAACCTCTGGTATTG \\
\hline F3L24 & 3 & 2849 & At3g09270 & $770 / 470$ & F: TGAGCAATGATGGTTAGCAG \\
\hline ГOLZ4 & 0 & 2.049 & (GSTU8) & 870 & R: GAACGTAACTGCTTACGTAG \\
\hline MZN24 & 3 & 7665 & At3g21750 & $1250 / 500$ & F: ATCCGAACCGAAATCAACTG \\
\hline MILINL4 & 0 & 1.000 & (UGT71B1) & $1200 / 000$ & R: GACTGAACGAGAGGAACATG \\
\hline MIL12 & 3 & 9194 & At3g25240 & $650 / 490$ & F: GGAGGCTAGAGACTCATATG \\
\hline 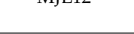 & 3 & 9.194 & 10 & 00070 & R: AGGGGATATTCGACTGAGAG \\
\hline Т6H 20 & 3 & 17243 & At3g46820 & $510 / 430$ & F: AGTCCACCATGCATACAAAG \\
\hline 101120 & 0 & 17.243 & (TOPP5) & $510 / 450$ & R: TGCATTGGTTTCTCTGCTTG \\
\hline CIW28 & 3 & 21.869 & At3g59140 & $630 / 450$ & F: GAGCACAAGTCTCTTACAAG \\
\hline CIV 20 & 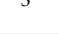 & 21.009 & $(A B C C 10)$ & & R: CCCTAAGTTTCACAAAGAATG \\
\hline T7M24 & 4 & 1788 & At4003826 & $1350 / 710$ & F: TTTGGCGCTGTTGCCAATTG \\
\hline 171ML4 & 4 & 1.700 & & & R: TAATGCGCGAGGTGGATATG \\
\hline $\mathrm{T} 32 \mathrm{~N} 4$ & 4 & 2549 & At40 04985 & $1180 / 900$ & F: CTCAAGGTCGACATGATAATG \\
\hline $1021 \mathrm{NA}$ & 4 & 2.049 & & & R: GTATAACGCGGGTCAATCTC \\
\hline F17A8 & 4 & 6109 & At40 09670 & $1280 / 560$ & F: TGCTCGAGAGACTTTTCGAG \\
\hline Г17AO & & 0.109 & & & R: CATAGACAGCCACACCAATG \\
\hline T2D20 & 4 & 9652 & At4g17200 & $420 / 360$ & F: TGGTCTTCTTATGCTCCAAG \\
\hline $12 \mathrm{D} 20$ & & 9.652 & & & R: AGAGGAAGCACACAGTATTG \\
\hline F8D20 & 4 & 16.924 & At4g35700 & $540 / 460$ & F: GGCGAGGATTGACTTAAATG \\
\hline FODZU & & 10.924 & $(D A Z 3)$ & & R: ACTGTTGCGATAATGCAGTG \\
\hline $\mathrm{F} 19 \mathrm{H} 22$ & 4 & 18.133 & At4g 38870 & $380 / 320$ & F: GCGTTGTTGAGTGTAGCAAG \\
\hline & & & & & R: GAGATCGATCGTCATCTTTC \\
\hline MBK20 & 5 & 2476 & At5g07770 & $410 / 350$ & F: AGAGACCCTTTTCTCTGTTG \\
\hline & & $2.4 / 0$ & $($ FH16) & & R: GGAGCTTACCATCATATCAG \\
\hline MPI7 & 5 & 5.902 & At5g17860 & $570 / 490$ & F: TCCAATTAGACCGCATATTAG \\
\hline MITIT & & 0.902 & $(C A X 7)$ & & R: TTCGTTGCTTGAGACACTAG \\
\hline T7I7 & 5 & 9271 & At5g26594 & $650 / 500$ & F: TGGCACCAAGAAGCAACTAG \\
\hline 1717 & 3 & 9.271 & $(R R 24)$ & & R: TCCTAACTATCAACCAACTTG \\
\hline K22F20 & 5 & 15,027 & At5o00540 & $490 / 420$ & F: ACCGCTACCATTTGTTCTTG \\
\hline АЕZГZU & & 10.027 & & & R: CCAACGTTCTTCCCTGTTAG \\
\hline DOG1 & 5 & 18.591 & At5g45830 & $1010 / 1300$ & F: GCGTGTTTGTGTTTTGTGTG \\
\hline DUGi & 3 & 10.391 & $(D O G 1)$ & $1010 / 1000$ & R: ATCCGCTGTCTCAGGACATC \\
\hline MMN10 & 5 & 24.108 & At5g59840 & $530 / 460$ & F: TGAAGGATGACTCGTCTGTG \\
\hline MIVINIO & 3 & 24.100 & (RABE1B) & & R: GATGGCTCTTTCACCACTAG \\
\hline
\end{tabular}

* Gene ID represents a gene that shows or is closest to the InDel polymorphism.

Figure 2 shows PCR-amplified fragments of the first recommended 15 markers in $0.8 \%$ agarose gels, which are arranged by the chromosome number $(\mathrm{I}-\mathrm{V})$ and position of each InDel marker. These markers exhibit clear difference in length. 


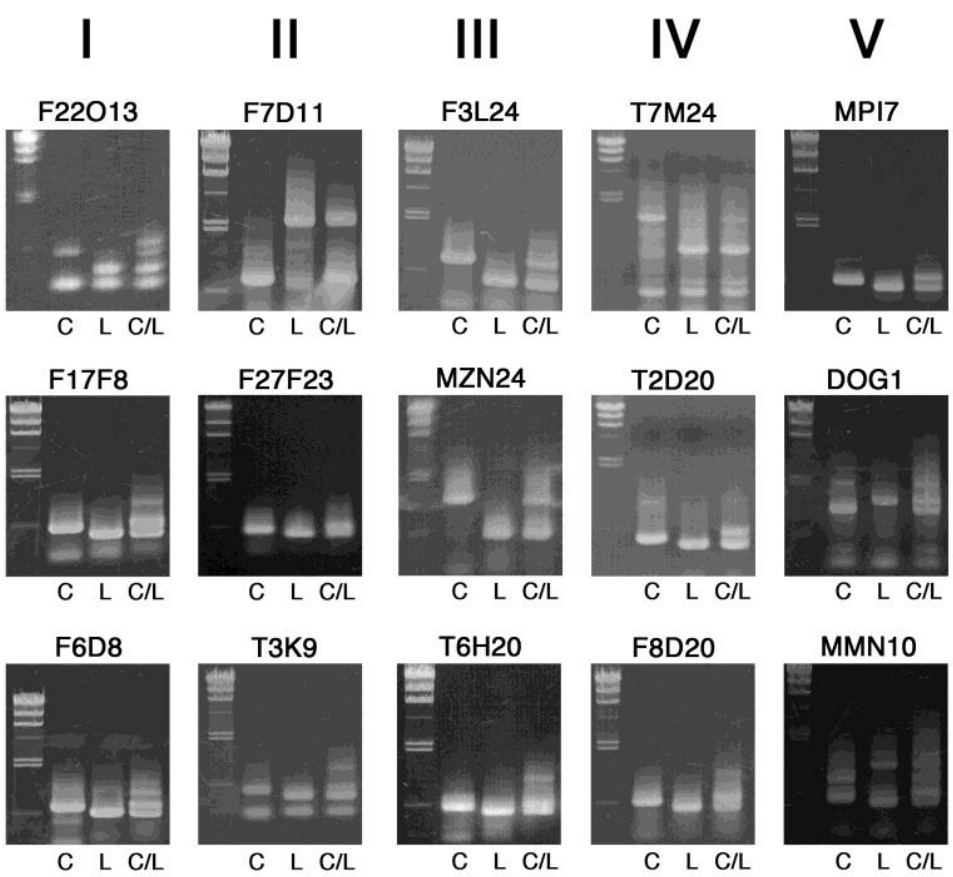

Figure 2. Band patterns of InDel markers useful for initial rough mapping. PCR-amplified DNA fragments were electrophoresed on $0.8 \%$ agarose gels, together with size markers of lambda DNA digested with HindIII $(23.1,9.4,6.6,4.4,2.3,2.0$ and $0.56 \mathrm{~kb})$ on the left side. C, L and C/L indicate template DNA from Col-0, Ler-0 and their F1 heterozygous progeny, respectively. The chromosome number is shown on the top.

Band patterns of PCR products of additional 15 markers, arranged by their chromosome number $(\mathrm{I}-\mathrm{V})$ and position, are shown in Figure 3 . These are also clear enough for genotyping in $0.8 \%$ agarose gels, which we routinely use. Although extra DNA bands are found in some markers, this may be further improved by modifying PCR conditions. The use of $1.0 \%$ or $1.2 \%$ gels would be better for higher resolution of the DNA fragments, in particular, with length less than $500 \mathrm{bp}$.

The list shown in this study is not exhaustive. A detailed study of the Ler-0 genome revealed that more than one hundred single-copy genes are only present in the reference sequence or the Ler-0 assembly [17]. This clearly suggests that the InDel markers suitable for fine mapping can be further developed. Together with all the other known polymorphic markers, the use of these InDel markers should make mapping experiments easier and accelerate functional analysis of genes with their point mutant alleles in Arabidopsis. Although we focused only on the most popular accessions Col-0 and Ler-0 in this work, some studies have identified mutants in Niederzenz-0 (Nd-0) [18] or other natural accessions. Some of the markers presented here are also expected to be applied to mapping experiments with these accessions. 

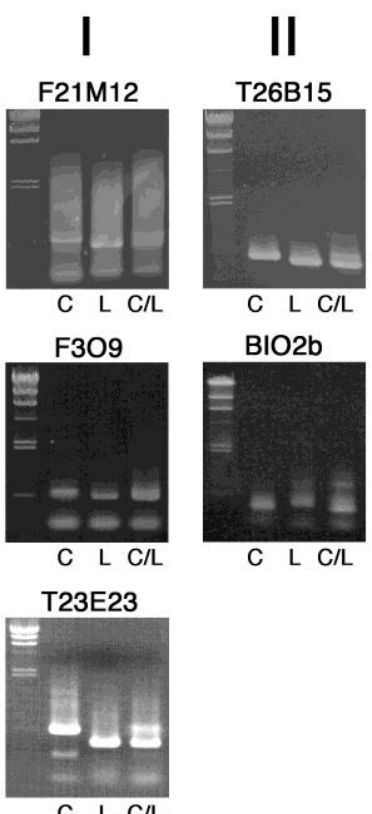

F24J13

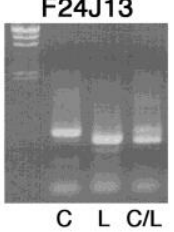

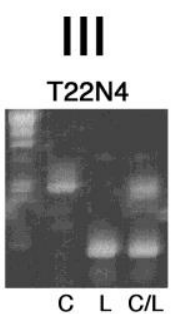
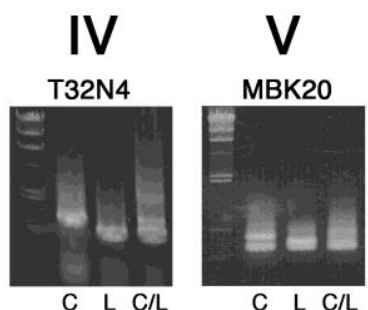

MJL12
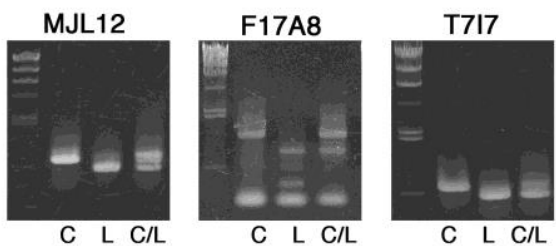

CIW28
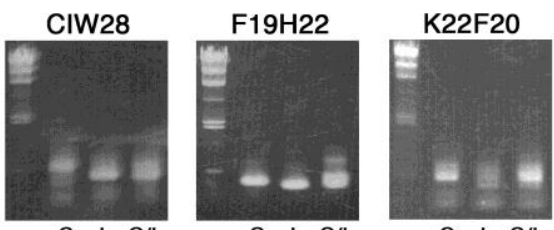

Figure 3. Band patterns of InDel markers for further mapping experiments. PCR-amplified DNA fragments were electrophoresed on $0.8 \%$ agarose gels, together with size markers of lambda DNA digested with HindIII $(23.1,9.4,6.6,4.4,2.3,2.0$ and $0.56 \mathrm{~kb})$ on the left side. C, L and C/L indicate template DNA from Col-0, Ler-0 and their F1 heterozygous progeny, respectively. The chromosome number is shown on the top.

\section{Materials and Methods}

\subsection{DNA Extraction}

Genomic DNA was extracted from a leaf or a seedling of Col-0, Ler-0 and their F1 progeny plants. The sample was ground with micro pestle in a 1.5-mL microtube for $30 \mathrm{~s}$. After addition of $120 \mu \mathrm{L}$ DNA extraction buffer that contains $0.2 \mathrm{M}$ Tris- $\mathrm{HCl}(\mathrm{pH} 8.0), 0.25 \mathrm{M} \mathrm{NaCl}, 25 \mathrm{mM}$ EDTA and 0.5\% SDS (w/v), the microtube was vortexed for $15 \mathrm{~s}$ and centrifuged at 15,000 rpm at room temperature for $10 \mathrm{~min}$. The supernatant of $100 \mu \mathrm{L}$ was transferred to another tube, mixed with $100 \mu \mathrm{L}$ isopropanol, and precipitated for $10 \mathrm{~min}$ in a freezer. DNA was collected by centrifugation at $12,000 \mathrm{~g}$ for $10 \mathrm{~min}$, rinsed with $100 \mu \mathrm{L}$ of $70 \%$ ethanol, dried under vacuum for $10 \mathrm{~min}$ and dissolved in $40 \mu \mathrm{L}$ TE buffer. After centrifugation at $12,000 \mathrm{~g}$ for $1 \mathrm{~min}$, the supernatant was used as a template DNA for PCR.

\subsection{PCR and Agarose Gel Electrophoresis}

PCR was performed using ExTaq polymerase (Takara, Kyoto, Japan) with 45 cycles of denaturation at $94{ }^{\circ} \mathrm{C}$ for $30 \mathrm{~s}$, annealing at $55^{\circ} \mathrm{C}$ for $30 \mathrm{~s}$ and extension at $72{ }^{\circ} \mathrm{C}$ for $90 \mathrm{~s}$. The PCR products were separated on $0.8 \%(\mathrm{w} / \mathrm{v})$ agarose gels in TAE buffer and visualized with ethidium bromide.

Author Contributions: Conceptualization, T.T. (Taku Takahashi); investigation, T.T. (Takahiro Tanaka), Y.N. and H.M.; validation, T.T. (Takahiro Tanaka) and T.T. (Taku Takahashi); writing, T.T. (Takahiro Tanaka) and T.T. (Taku Takahashi); funding acquisition, T.T. (Taku Takahashi). All authors have read and agreed to the manuscript content.

Funding: This work was supported in part by the Japan Society for the Promotion of Science (JSPS) Grants-in-Aid for Scientific Research (Nos. 19K06724) to T. Takahashi. 
Conflicts of Interest: The author declares no conflict of interest.

\section{References}

1. Jander, G.; Norris, S.R.; Rounsley, S.D.; Bush, D.F.; Levin, I.M.; Last, R.L. Arabidopsis map-based cloning in the post-genome era. Plant Physiol. 2002, 129, 440-450. [CrossRef] [PubMed]

2. Peters, J.L.; Cnudde, F.; Gerats, T. Forward genetics and map-based cloning approaches. Trends Plant Sci. 2003, 8, 484-491. [CrossRef] [PubMed]

3. Jiang, W.; Zhou, H.; Bi, H.; Fromm, M.; Yang, B.; Weeks, D.P. Demonstration of CRISPR/Cas9/sgRNA-mediated targeted gene modification in Arabidopsis, tobacco, sorghum and rice. Nucleic Acids Res. 2013, 41, e188. [CrossRef] [PubMed]

4. $\quad$ Feng, Z.; Mao, Y.; Xu, N.; Zhang, B.; Wei, P.; Yang, D.-L.; Wang, Z.; Zhang, Z.; Zheng, R.; Yang, L. Multigeneration analysis reveals the inheritance, specificity, and patterns of CRISPR/Cas-induced gene modifications in Arabidopsis. Proc. Natl. Acad. Sci. USA 2014, 111, 4632-4637. [CrossRef] [PubMed]

5. Fauser, F.; Schiml, S.; Puchta, H. Both CRISPR/Cas-based nucleases and nickases can be used efficiently for genome engineering in Arabidopsis thaliana. Plant J. 2014, 79, 348-359. [CrossRef] [PubMed]

6. Gao, X.; Chen, J.; Dai, X.; Zhang, D.; Zhao, Y. An effective strategy for reliably isolating heritable and Cas9-free Arabidopsis mutants generated by CRISPR/Cas9-mediated genome editing. Plant Physiol. 2016, 171, 1794-1800. [CrossRef] [PubMed]

7. Konieczny, A.; Ausubel, F.M. A procedure for mapping Arabidopsis mutations using co-dominant ecotype-specific PCR-based markers. Plant J. 1993, 4, 403-410. [CrossRef] [PubMed]

8. Glazebrook, J.; Drenkarci, E.; Preuss, D.; Ausubel, F.M. Use of cleaved amplified polymorphic sequences (CAPS) as genetic markers in Arabidopsis thaliana. Methods Mol. Biol. 1998, 82, 173-182. [PubMed]

9. Bell, C.J.; Ecker, J.R. Assignment of 30 microsatellite loci to the linkage map of Arabidopsis. Genomics 1994, 19, 137-144. [CrossRef] [PubMed]

10. Neff, M.M.; Neff, J.D.; Chory, J.; Pepper, A.E. dCAPS, a simple technique for the genetic analysis of single nucleotide polymorphisms: Experimental applications in Arabidopsis thaliana genetics. Plant J. 1998, 14, 387-392. [CrossRef] [PubMed]

11. Hou, X.; Li, L.; Peng, Z.; Wei, B.; Tang, S.; Ding, M.; Liu, J.; Zhang, F.; Zhao, Y.; Gu, H.; et al. A platform of high-density INDEL/CAPS markers for map-based cloning in Arabidopsis. Plant J. 2010, 63, 880-888. [CrossRef] [PubMed]

12. Pacurar, D.I.; Pacurar, M.L.; Street, N.; Bussell, J.D.; Pop, T.I.; Gutierrez, L.; Bellini, C. A collection of INDEL markers for map-based cloning in seven Arabidopsis accessions. J. Exp. Bot. 2012, 63, 2491-2501. [CrossRef] [PubMed]

13. Zhang, Y.; Glazebrook, J.; Li, X. Identification of components in disease-resistance signaling in Arabidopsis by map-based cloning. Methods Mol. Biol. 2007, 354, 69-78. [PubMed]

14. Xing, J.; Weng, Q.; Si, H.; Han, J.; Dong, J. Identification and molecular tagging of two Arabidopsis resistance genes to Botrytis cinerea. Front. Agric. China 2011, 5, 430-436. [CrossRef]

15. Bryant, F.; Hughes, D.; Hassani-Pak, K.; Eastmond, P. Basic LEUCINE ZIPPER TRANSCRIPTION FACTOR67 transactivates DELAY OF GERMINATION1 to establish primary seed dormancy in Arabidopsis. Plant Cell 2019, 31, 1276-1288. [CrossRef] [PubMed]

16. Mitsuhashi, M. Technical report: Part 2. Basic requirements for designing optimal PCR primers. J. Clin. Lab. Anal. 1996, 10, 285-293. [CrossRef]

17. Zapata, L.; Ding, J.; Willing, E.M.; Hartwig, B.; Bezdan, D.; Jiao, W.B.; Patel, V.; Velikkakam James, G.; Koornneef, M.; Ossowski, S.; et al. Chromosome-level assembly of Arabidopsis thaliana Ler reveals the extent of translocation and inversion polymorphisms. Proc. Natl. Acad. Sci. USA 2016, 113, 4052-4060. [CrossRef] [PubMed]

18. Sahu, B.; Sumit, R.; Srivastava, S.; Bhattacharyya, M. Sequence based polymorphic (SBP) marker technology for targeted genomic regions: Its application in generating a molecular map of the Arabidopsis thaliana genome. BMC Genom. 2012, 13, 20. [CrossRef] [PubMed]

(C) 2020 by the authors. Licensee MDPI, Basel, Switzerland. This article is an open access article distributed under the terms and conditions of the Creative Commons Attribution (CC BY) license (http://creativecommons.org/licenses/by/4.0/). 